\title{
Language quotient (LQ): new models of language learning
}

\author{
Mohammed Ilyas* \\ Department of English, College of Science and Humanities, Prince Sattam Bin Abdulaziz University, Saudi Arabia
}

\section{ARTICLE INFO}

\section{Article history:}

Received 15 June 2016

Received in revised form

26 August 2016

Accepted 19 September 2016

\section{Keywords:}

Language quotient

Psychological tests

New models

\begin{abstract}
A B S T R A C T
This paper is an outcome of a research carried out initially to measure level of linguistic competence of learners in an ESP situation, engineering students, to be specific, where the variety of contexts needed different learning strategies to get the required learning outcomes. The linguistic competence was determined by calculating Language Quotient (LQ), after Eysenck's method of finding the Intelligence Quotient (IQ) The LQ helped the researcher to find out whether the linguistic competence of a learner is either advanced or retarded, good, average or below average. Encouraged by the findings, the researcher recently carried out several subtests, supplemental tests and associative tasks in various testing areas at all levels like reading, writing, grammar, vocabulary, syntactic and morphological structures and phonological processing. This research paper shares a few of these strategies to determine how LQ method of assessing linguistic competence can be particularly useful in large classrooms and with learners belonging to heterogeneous groups and even in a foreign language environment.
\end{abstract}

(C) 2016 The Authors. Published by IASE. This is an open access article under the CC BY-NC-ND license (http://creativecommons.org/licenses/by-nc-nd/4.0/).

\section{Introduction}

The Second Language (L2) acquisition is although a socio-cultural and psychological phenomenon, it also depends upon various personal factors like attitude, skills and capabilities that one can learn and practice. In many universities across the globe, the English Language has been adopted as a medium of instruction for most of the ESP courses, including the engineering curriculum. A great challenge before the ESP faculty is therefore to identify the special learning needs of students in order to design a more need-oriented curriculum, based on ESP principles.

It is indeed a great challenge to assess the linguistic competence of an engineering student at the time of admission. Students come from diverse backgrounds and especially those from a vernacular background find the examination of English Language a very difficult task to get even a pass grade. Many curriculum framers look for a method by which they can identify the English Language needs of an engineering student in his very first level of graduation. Teachers and Faculty too design

\footnotetext{
* Corresponding Author.

Email Address: m.ebrahim@psau.edu.sa

https://doi.org/10.21833/ijaas.2016.09.008

2313-626X/@ 2016 The Authors. Published by IASE

This is an open access article under the CC BY-NC-ND license

(http://creativecommons.org/licenses/by-nc-nd/4.0/)
}

innovative methods to diagnose the language proficiency of a student. This research study is an outcome of the author's two-decade long teaching career in an engineering college, prior to advancing into his current position and developing research interests in EFL situations where the application of LQ measurement shall prove to be very useful.

In order to determine $\mathrm{LQ}$, the author had concurrently designed a complete package consisting of Objective Tests, a learning grid and an assessment tool, scientifically proven and also tested through practical application for many years. This assessment tool was particularly useful to diagnose the linguistic competence of students of large classes and of heterogeneous groups. This method was called by the author LQ Method of Assessment, based on Eysenck's (Eysenck, 1962) method of finding the Intelligence Quotient (IQ) where LQ stands for Language Quotient. This tool also helped the teacher to identify the deficiencies and the learning needs of the students and determine the language skills requirement at the beginning of a semester in order to design a needs-based curriculum focusing on the learning gaps as revealed by this assessment tool.

In this research paper the author improvises the concept of Language Quotient (LQ), even more broadly and goes a few steps farther. Several subtests and associative tasks were carried out: for example a syntactic subtest was designed to assess students' ability to understand meaning of sentences 
having different syntactic structures as well as recognize and use common English morphological forms; a phonological subtest was given to assess their ability to recognize differences in speech sounds and a grammar subtest was provided to test their ability to construct correct sentences. Such acronyms like Spoken Language Quotient (SLQ), Listening Quotient (LiQ); Semantic Quotient (SeQ), Syntax Quotient (SyQ) can be coined indigenously, each referring to a particular testing area under the broad perspective of LQ.

This research paper shall first recollect and explain in detail the diagnostic model of finding LQ in order to provide a base to this empirical study; followed by explaining the logical relevance in conducting subject specific sub tests and supplemental tests in various testing areas in the light of a few underpinning theories and intelligence models.

\section{Methodology}

The LQ can be obtained by administering a simple test or a sub test on specific areas of curriculum and applying a pertinent mathematical formula. This concept is quite akin to finding Emotional Quotient (EQ) or Intelligence Quotient (IQ). Evidences have been collected that students who take the LQ tests at regular intervals demonstrate a great change in their learning and comprehension of the English Language. The LQ also helps to improve the teacher's effectiveness as $\mathrm{s} / \mathrm{he}$ can modify teaching strategies or activities based on the results of the tests.

The LQ method of Testing and Assessment is done by a simple, objective test of English Language carrying 40 questions. Students are asked to attempt maximum number of questions in a given time. The percentage of right answers given by each student determines his Language Quotient (LQ). Since LQ is primarily obtained to determine the learning needs of an engineering student at Level 1 , it is recommended to follow certain principles of evaluation.

First of all, the LQ Tests should relate directly to instructional objectives. These are also standard learning objectives of a course under study. Second, the teacher must know what types of items can be included. In order to determine the scope of the test holistically, every single objective and competency required to master by the student must be dealt with in the test. For instance, if a learning objective is to improve reading and writing skills, the test must include items that test the learners on these areas. Third, it is important to determine how much will each objective be worth in terms of weightage and number of items in a test.

There should also be flexibility in the form of the LQ test. It can be a Paper and Pencil Test or an Online Test using the ICT techniques. Computers recently have been a great aid in language learning so if equipment and knowhow is available, it is strongly recommended to administer LQ tests through online methods. The type of question could be Limited Choice Questions viz. multiple choice, True or False and Matching.

LQ also helps to find out student's "mental age" as against his "chronological age", two terms very popular in IQ situation. The mental age helps to rate the LQ of a student as either advanced or retarded. This is done with an ordinary graph with a predrawn diagonal line (see Fig. 1). The score is entered on the base line and the LQ on the vertical line. After taking a test, a student is asked to mark his score on the base line and to draw a straight line until it meets the diagonal line. The point on the vertical line corresponding to the meeting point on the diagonal line gives him his LQ. An LQ of 100 is worked out as average after having observed that a student often succeeds in answering 50\% of total questions correctly. However, this can vary from test to test. A more difficult test or the same test to another group would rate $40 \%$ or $60 \%$ as the average score and so on.

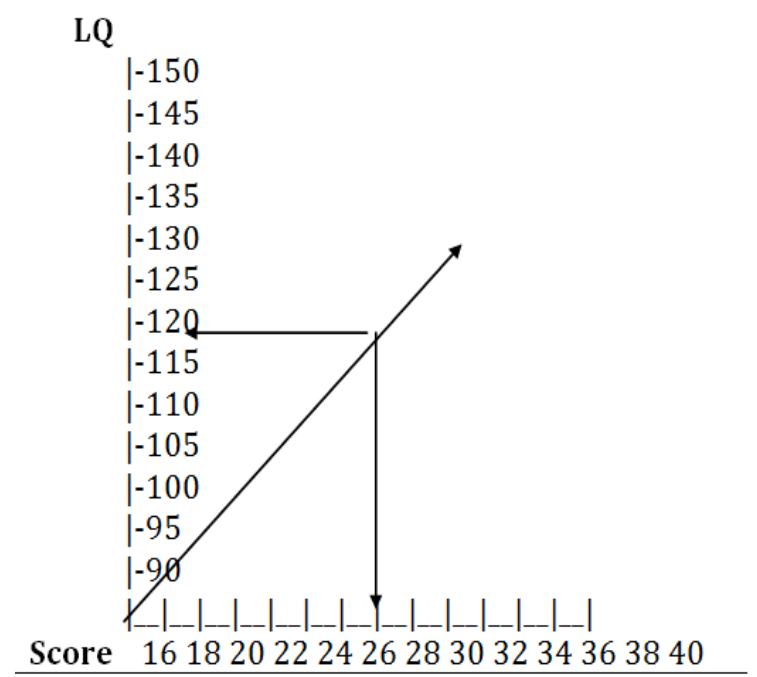

Fig. 1: Showing LQ according to test score

\section{Field of study}

In a given semester, when this study was conducted, 380 engineering students in Level 1 of their degree program were asked to take this test. The test was made mandatory for all the students as the instructor told them in advance that the score would determine their learning needs. Moreover, their choice of courses in subsequent semester also depended on the level of English language they possess or the credit they score in Level 1. For instance, if their language competence showed drastic deficiencies, they would normally be allowed to opt humanities courses which include courses in literature as well. The students' ages varied from 18 to 22 years and the average age was worked out to be 20.4 years.

A total of 360 students appeared in the Test. The test carried 40 questions with one mark for each correct answer. There was no negative marking. The results were astonishing as a large segment of the test-takers were from the vernacular background. 
For ease of calculation and providing an easy feedback, the students were divided into three age groups: (1) Less than 18 years; (2) 19 to 20 years and (3) more than 20 years. The total attendance in the test for each age group and marks scored is shown in Table I and graphically presented in Fig. 2.

After the test was complete, the students were notified about their score and the LQ obtained with the score. For example, if a student's score was 28 out of 40, his LQ would be 120. An LQ of 120 was rated as above average or even good but an LQ of 80 or 60 was below average or even poor. It was observed that after the test was conducted, each student was curious to know his LQ as one is curious to know one's IQ. To make it more interesting and in order to make students realize the importance and seriousness of such tests, a simple mathematical calculation was also done to calculate the student's mental age as against his chronological age:

$M A=\frac{L Q \times C A}{100}$

Where MA refers to Mental Age, LQ refers to Language Quotient and CA stands for Chronological age (Table 1).

Table 1: LQ scores- group wise

\begin{tabular}{|c|c|c|c|c|c|c|}
\hline \multirow{2}{*}{$\begin{array}{c}\text { Age Group } \\
\text { Number of students }\end{array}$} & $>20$ & $20-25$ & $26-30$ & $31-35$ & $36-40$ \\
\hline$>18$ years & 40 & 21 & 8 & 5 & 5 & 1 \\
\hline $19-20$ years & 248 & 110 & 70 & 55 & 10 & 3 \\
\hline$<20$ years & 72 & 40 & 20 & 6 & 4 & 2 \\
\hline Total & 360 & 161 & 98 & 66 & 19 & 6 \\
\hline
\end{tabular}

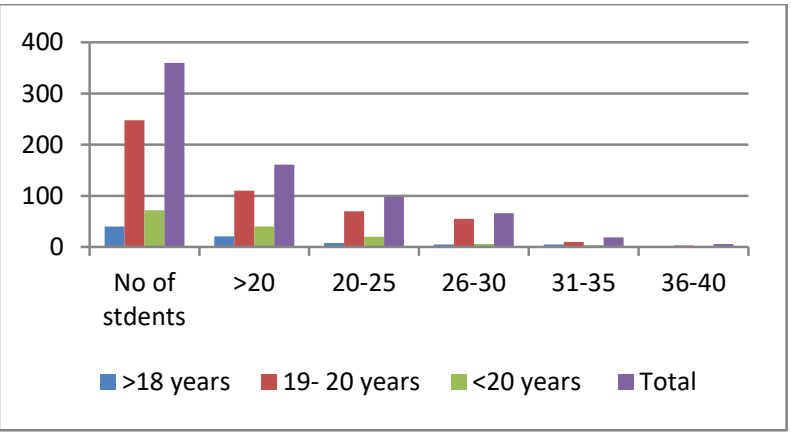

Fig. 2: Marks scored in each age group

For example, at the age of 18 if a student takes up such a test of English Language and gets a score of 120 , his mental age shall be

$$
M A=\frac{120 \times 18}{100}=21.6 \text { years, } 3.6 \text { years advanced } \text {. }
$$

Therefore, a student's competence of the English language, in terms of intelligence or dullness, gets reflected in terms of difference between his mental age and chronological age. Thus a student of 18 years with a mental age of 16 years would be 2 years retarded while another student of same age obtains a mental age of 21 would be 3 years advanced. A LQ table was also prepared as a quick reference for the students to check their Mental Age (MA) instantly.

Having obtained results of the LQ test, the next step was to use the LQ scores to determine the learning needs of individual students. The students were segregated in sections according to their LQ. The course curriculum was also customized for each section. Students with low LQs were required to undergo an aggressive mode of learning and acquiring knowledge and skills while those with higher LQs were given analytical exercises to improve their creativity and cognitive skills. In other words, a blue print was prepared plotting the objectives and competencies using Bloom's Taxonomy (Bloom et al., 1956) of Educational
Objectives wherein a student's level of learning corresponds to the course content. This blueprint was a kind of hierarchy representing levels of cognitive difficulty as well as depth of processing from higher order cognitive skills to lower order cognitive skills.

LQ is not only a measure of assessing the present linguistic ability of a student but such tests can be conducted after every 3 months and each time the LQ tends to go higher or lower as a mark of improvement or further retardation. It can also help the teacher to identify the changing specific needs of his students and to recommend which student should pursue a language course or a remedial workshop and of what nature -- intensive or extensive, short term or long term and so on. In this way a student gets multiple opportunities to improve his language proficiency and upgrade his LQ and MA as well. On the basis of LQ, the teacher can also classify learners into different groups like Bright, Average, Below Average or Dull. Each group has a specific learning requirement. The teaching of the curriculum can now also be taken up at each group level, which will enable the teacher to prescribe suitable tutorial exercises and home assignments group wise and also to mould his teaching accordingly. This method can further be utilized to assess the competence of other subjects also viz. mathematics, physics, biology, and so on. It not only saves time but also gives the accurate assessment of the student.

\section{Underpinning theories}

A study of human intelligence through psychometric measurements requires a high level of theoretical evidence. There are various underpinning theories that are pertinent to the context of LQ in the current study. For instance, Bloom taxonomy is best understood in a pyramid which projects six levels of learning objectives: 
Evaluation on the top, followed by Synthesis, Analysis Application Comprehension and finally knowledge (Fig. 3).

\section{Higher order thinking skills}

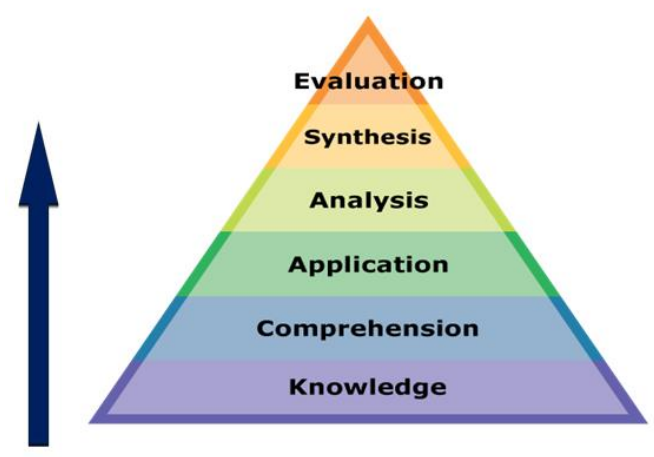

Lower order thinking skills

Fig. 3: Bloom's taxonomy (Bloom et al., 1956)

It means the higher a student goes in his learning competences, the higher is the order of his thinking skills. Accordingly, the teacher can shuffle, rotate and customize the items of the course curriculum to ensure the desired learning outcome. In the case of LQ, the students with higher scores should be placed at the top of the pyramid and assigned analytical and evaluative exercises that require higher order thinking skills. For instance, these students are ideally suited to writing reports, conduct and evaluate experiments while students with low LQs are required to undergo remedial exercises to improve their thinking skills.

There is an additional burden on the teacher to keep records of the scores as the learner moves from lower order thinking to higher order thinking skills. It is also important to study how consistent is the improvement ratio of the learner's LQ, even necessitating fresh LQ tests at frequent intervals. This practice is often seen in compliance of the Flynn Effect theory, named after James Flynn, an American professor of psychology in New Zealand, who observed a standardized and consistent improvement in the IQ scores of average American students over decades. The Flynn effect infers that if a learner takes the older version of an IQ test, his IQ score will be higher in comparison with the score that he attains when he takes the revised version of the same test. In other words the Flynn's Effect observes an increase of three points per decade in an individual's IQ score. (Flynn, 1984; 2009) Specifically speaking, Flynn asserts that if the average IQ score is 100 at any given time, and if an individual takes a test from a century ago, he would score brilliantly a high average IQ of 130; and if an individual of 100 years ago had taken today's tests, he would have an average IQ of 70 .

There is one similarity between Bloom's Taxonomy and Flynn's Effect. While Bloom emphasizes that the course content for each level of study must correspond to the learner's cognitive abilities or competence to cope up with level of difficulty in understanding it for which he strongly advocates a pro rata increase in the thinking skills, the Flynn's effect also predicts a substantial increase in the learner's knowledge passing through various stages of intelligence and cognitive abilities to take tests at next higher levels. However, there is one difference too. While Bloom's taxonomy depends upon a systematic process of his pyramid, Flynn accredits the increase in the intelligence level to the external factors like technology that are making the present generation smarter than their predecessors. (Flynn, 2009) He strongly believes that the change in IQ scores of learners is mainly due to industrialization and information based activities thus making people better at thinking about the abstract and scientific terms. Hence when learners take various IQ or LQ tests and sub tests, they can make use of their abstract thinking in a much better way. Moreover, in developed nations, students stay longer in school, teaching methods also have been evolved and teacher-student interactions are also more intellectual - all leading to the conclusion that education is training people to think well.

During the course of this experimentation the researcher came across a closely related pedagogical theory based on a student's judgment and ability to take a test according to his or her individual capacity of 'proximal development' (Vygotsky, 1978). The difference between a student's actual developmental level and his or her potential is the zone of proximal development (ZPD). The theory states that good instruction principles backed by an intelligent support system help the teacher to improve a student's ZPD. The researcher observes that a student who takes a LQ test is actually introspecting his ZPD and evaluating his capacity to acquire higher thinking skills by improving the deficiencies he discovers in understanding the curriculum. Though the limitation of the ZPD theory is how to determine the testing areas or what abilities and skills comprise the intelligence of a learner.

Logically, the testing of a learner's intelligence should not be much different from testing his linguistic abilities and the related skills; making the calculation of LQ akin to that of IQ. (Flanagan and Harrison, 2005) Psychologists however have a debate over this issue, particularly Raymond Catell, John Horn and John Carroll, who are known for their Cattell-Horn-Carroll theory, abbreviated as CHC Theory, who redefined their own previously established theoretical models of general intelligence: crystallized intelligence and fluid intelligence (abbreviated as Gf and Gc) (McGrew, 2005; Schneider and McGrew, 2012). A combination of these two models is used in numerous IQ scales to determine the IQ score. The first type refers to such information accumulated through knowledge and information gained from subjects like mathematics, grammar and verbal skills while the latter type comprises skills of vocabulary and general knowledge. The synthesized knowledge also termed as crystallized knowledge is considered to increase with age and the student accumulates knowledge and information. The CHC theory takes forward the 
Gf and Gc model and postulates a hierarchy of human cognitive abilities and included broadly abilities like auditory, visual and short term and long term memory retrieval among a few others.

Last, but not the least, Howard Gardner postulated a multiple intelligence theory comprising intelligence types like linguistic, logical, interpersonal and intrapersonal (Gardner, 2016). Proposed in 1983, the theory focused more on behavior rather than intelligence. Gardner asserted that intelligence depends on the conditions of brain and opposed labeling individuals on the basis of one single, specific intelligence. According to him, if there are multiple intelligences, it would "empower" students and will not restrict learning. In his multiple intelligence theory are included abilities like verbal-linguistic, interpersonal and intra personal among others.

The concept of LQ however is beyond such a debate or controversy over the definition or types of intelligence. All theories have recommended testing of linguistic skills or verbal skills as a part of intelligence and so do many educational programs across many universities have these skills as a part of their curriculum. Therefore, finding a score of LQ of a learner at various stages of learning not only enables the faculty to determine his pace of learning and determine testing areas, it also helps the institution to accomplish the learning objectives.

\section{Testing areas}

There are no fixed testing areas on which Language Quizzes and Tests can be based to determine the LQ of a student. The author recommends focusing on the prescribed curriculum and its contents. The curriculum and the course description of a subject under study is an authentic reference to design a $\mathrm{LQ}$ Test. In other words, a teacher cannot randomly design a questionnaire and administer it to obtain LQ. The test items must relate with the curriculum or the course description under study. Generally speaking, LQ tests at level 1 can be constructed in the following testing areas:

- Parts of speech

- Fundamentals of grammar

- Sentence composition

- Word formation and order of words

- Vocabulary (general and specific)

- Reading comprehension

- Speaking and listening skills

- Paragraph writing

The LQ tests can be constructed with different types of Test Questions:

- Multiple-Choice Items

- True-False Items

- Shot answer items (e.g. matching items, Fill-In, Completion)

For constructing Multiple Choice Test Items, we need to follow certain rules:

- Items should have 3-4 alternatives.

- Stem should present a single, clearly formulated problem
- Use simple and understandable words from both stem and alternatives

- Do not include in the stem any word that is repeated in a response

- Avoid choice 'All of the above' or 'None of the above'

For constructing True-False Test Items, generally follow these rules:

- Avoid double negatives

- Avoid long or complex sentences

- Specific determiners like 'always', 'never', 'only' should be used with caution

- To have only one central idea in each statement

- Avoid emphasizing the trivial

- Exact quantitative (two, three, four) language is better than qualitative (some, few, many)

For constructing Short Answer Test Items, we keep these things in mind:

- Better to supply the term that requires a definition

- For numerical questions, the degree of precision and the units of expression must be known.

- Use direct questions rather than incomplete statements

- Try to phrase items so that there is only one possible correct response

- When incomplete statements are used, do not use more than one blank within an item.

For higher levels, too, the LQ assessment model can be modified and improvised for testing areas like Syntax, morphology, phonological processes, reading and writing, speaking and listening. For instance, a syntactic subtest can be designed to assess student's ability to understand meaning of sentences having different syntactic structures as well as recognize and use common English morphological forms; a phonological subtest can be given to assess his ability to recognize differences in speech sounds and a grammar subtest can be provided to test his ability to construct correct sentences and so on. Such acronyms like Spoken Language Quotient (SLQ), Listening Quotient (LiQ); Semantic Quotient (SeQ), Syntax Quotient (SyQ) can be attempted indigenously, each referring to a particular testing area.

While conducting sub tests, it is important to focus on the pertinent areas. For instance, in a sub test to assess syntactic awareness, students are required to do sentence combinations and construct grammatically correct sentences from a group of two or more sentences. For example, 'We went for a walk' and 'It was after supper' can be combined into 'We went for a walk after supper.' A study conducted by Hammill et al. (2007) further illustrates consistency and reliability of such sub tests requiring combination of sentences. Layton et al. (1998) had also developed a Syntactic Awareness Questionnaire to assess high level knowledge of Syntax.

Similarly, in a phonological subtest, the learners may be asked to blend words after listening to a stimulus item. A CD is played carrying different sounds and the students are asked to recognize and put the separate sounds together and make a whole 
word. In other words, this subtest aims at testing the student's ability to combine sounds to form words. In another subtest, students may be asked to segment words by repeating words as they hear, stressing upon each of its sound, that is, to measure their ability to say the separate phonemes that make up a word, the one at the start, in the middle and at the end. A phoneme reversal subtest can also be carried out to assess the extent to which students can rearrange sounds heard to form words. The teacher can also play a few pre-recorded non words and students are asked to first say those non words, and then to say them again backwards to form a real word.

In the writing subtest, students may be tested on editing and correcting illogical and redundant sentences to bring better sense. For example, to show agreement, the sentence like 'Ali shook his head' should be changed into 'Ali nodded his head' or 'He slapped her face' to be changed into 'He slapped her' as more logical sentences. These subtests are carried out to check whether students can write extraneous information and frequently use run-on sentences.

In a vocabulary subtest, similarly, the student may be asked to explain multiple meanings of a word in different contexts; e.g. very simple words like book, fire, paper and water; can be used as verbs, nouns and adjectives in their contexts. This will be a test of the student's ability to use synonyms and understand the appropriate meaning of words in their contexts. He may also be given a word fluency subtest and asked to utter as many words as he can recall or a substitution subtest in which he substitutes a word or a part of it, its prefix or the suffix. A verbal ability subtest may also be designed as a part of calculating LQ score that would bring it still closer to IQ tests in similarity. This subtest would require testing a student's ability to understand verbal descriptions through stimulus questions. The LQ score of this segment will be a reflection of his level of prior acquisition of language.

Each of these subtests requires approximately 60 -90 minutes and during the administration of each sub test it is observed that students with average abilities also show interest in taking the test and score higher gradually as they take a third or fourth test over a time period. The teacher incentivises students each time by changing his group to the next level. The student is also told about his mental age and whether s/he is advanced or retarded. Such an indigenous application of the results of the subtests and LQ score can strengthen the teacher's pedagogy and his teaching strategies.

\section{Pedagogy}

The pedagogy of a learner-centered classroom is always integrated with the learners. In other words, the teacher cannot deviate from the learning needs of individual students. After evaluating the current learning needs of a student through LQ tests, the teacher discusses with the class specific items to study and methods to learn those items before designing a lesson plan and a teaching framework.

Language Quotient (LQ) can be equated very closely with psychometric tests so vividly used in training and industrial situations. The 'psycho' part in 'psychometric' means that the test assesses a characteristic that is something to do with psychology or how the human brain works - usually to assess some aspect of intelligence or personality. The 'metric' part means that the test provides a measurement of the relevant characteristic[s] of the subject under study. It is a numerical score that describes how much of learning one has in comparison to other people.

There are many similarities and dissimilarities between psychometric tests and LQ tests. In both types of tests, the questions should have both right and wrong answers; they should have alternatives and difficulty level must increase as one takes the test. In psychometric test, it is not necessary to finish the test; IQ is determined by the number of correct answers attempted by the student. But in LQ tests, one must attempt all the questions in the given time and there is no negative marking. In both types of tests, the score of a student is compared with that of other students who had taken the same test at the same time.

Both types of test will enable examiners to assess one's knowledge in a particular testing area and to determine one's ability to manage a challenging situation or execute a task in the industry as he advances in his life and career. Both types require assessing the validity of such tests and their compatibility with the learning objectives as well as the skills required to do a job. Both tests emphasize overall or 'general' as well as 'particular' type of intelligence required to study a subject or do a job therefore any kind of knowledge, skill or ability that is seen as a requirement to learning or to do the job well would potentially be assessed in these tests. One good thing about these tests is that the learner understands that these tests are meant to assess their potential to learn whether they are capable of acquiring something new or being more flexible in a learning situation and adapting to change quickly. These tests are meant for those who can apply their knowledge, skills and attitude to their learning and also develop new skills simultaneously.

Shewan (1986) evolved a unique measurement technique for patients of Dyslexia, or poor shortterm memory and interestingly called it too "Language Quotient (LQ)a new measurement technique, in which LQ score was a kind of "summary score" which tests a student's auditory and oratory skills, reading and writing comprehensions, particularly administered on patients suffering from dyslexia. A kind of verbal test was administered on patients who show irregular speaking and listening skills since they cannot remember what has already been said and what still needs to be said. This may even happen with a normal person when he forgets a name or a date or cannot find a right word to express his meaning. 
Similar problems can arise in listening. One may find it difficult to follow a discussion or a conversation holistically. One may realize that one has forgotten some instructions that have been given. One may also interrupt others feeling that if they talked longer, one may forget what has been said or what one wants to say.

A few Intelligence tests like Wechsler Intelligence Scale for Children (WISC), developed by David Wechsler (Wechsler, 2014) or Stanford-Binet Intelligence Scales Fifth Edition (SB-5) developed by French psychologist Alfred Binet and Theodore Simon (initially known as Binet-Simon Test) can also be mentioned here in the context of. LQ. The WISC tests were used to measure the intelligence quotient (IQ) score to represent a child's general intellectual ability. The test areas which included Verbal Comprehension, too, investigated a child's cognitive domains and identify deficiencies and specific learning disabilities including, dyslexia and dyscalculia. These tests can be administered on all age groups from infants to adults and are reported to have a standardized increase in IQ scores which is consistent with Flynn's claims made earlier. The second type, Standord-Binet test is also a scale that diagnoses and measures verbal and nonverbal deficiencies among children and adults. The subtests include testing areas like comparisons, verbal knowledge (names) of objects and pictures, repetition of sounds, words synthesis and like. It was revised in 2003 (Ruf, 2003) and more dimensions of intelligence were added to it. According to this edition, an IQ of 130 or above was considered to be very advanced and gifted; while an IQ less than 70 was counted to be impaired or retarded. Both these tests are currently used in clinical as well as neuropsychological assessments, educational placement tests, career evaluation practices, and their scores are highly acceptable in both civil and military professions (Fancher and Rutherford, 2012).

\section{Conclusion}

However, the author, in this research paper, has interpreted LQ in an academic context. The students pursuing the engineering curriculum are required to take a simple test on the four skills: speaking and listening, reading and writing; though there can also be customized tests on other aspects of language like grammar, syntax or vocabulary. It has thus become scientifically possible to diagnose the linguistic competence of students of large classes and of heterogeneous groups. The student does not have to wait till the end of the session to know his linguistic competence. He comes to know instantly what his present knowledge of English Language is. This method has been widely accepted by university teachers and acclaimed for its originality.

\section{References}

Bloom BS, Engelhart MD, Furst EJ, Hill WH, Krathwohl DR (1956). Taxonomy of educational objectives: The classification of educational goals. Handbook I: Cognitive domain, David McKay Company, New York, USA.

Eysenck HJ (1962). Know your own IQ. Penguin (Non-Classics), W. H. Allen and Co., London, UK.

Fancher RE and Rutherford A (2012). Pioneers of psychology. W. W. Norton and Company, Inc., New York, USA.

Flanagan DP and Harrison PL (2005). Contemporary intellectual assessment: Theories, tests, and issues. $2^{\text {nd }}$ Edition, The Guilford Press, New York, USA.

Flynn JR (1984). The mean IQ of Americans: Massive gains 1932 to 1978. Psychological Bulletin, 95(1): 29-51.

Flynn JR (2009). What is intelligence: beyond the Flynn effect. Expanded paperback Edition, Cambridge University Press, Cambridge, UK.

Gardner H (2016). Multiple Intelligences: New Horizons in Theory and Practice. Basic Books, New York, USA.

Hammill DD, Brown VL, Larsen SC and Wiederholt JL (2007). Test of Adolescent and Adult Language. $4^{\text {th }}$ Edition, PRO-ED, Inc., Austin, USA.

Layton A, Robinson J and Lawson M (1998). The relationship between syntactic awareness and reading performance. Journal of Research in Reading, 21(1): 5-23.

McGrew KS (2005). The Cattell-Horn-Carroll theory of cognitive abilities: Past, present, and future. In: Flanagan DP, Genshaft JL and Harrison PL (Eds.), Contemporary intellectual assessment: Theories, tests, and issues. Guilford, New York, USA: 136182.

Ruf DL (2003). Use of the SB5 in the Assessment of High Abilities. (Stanford-Binet Intelligence Scales, Fifth Edition Assessment Service Bulletin No. 3), Riverside Publishing, Itasca, Illinois, USA.

Schneider WJ and McGrew KS (2012). The CattellHorn-Carroll model of intelligence. In: Flanagan D and Harrison P (Eds.), Contemporary intellectual assessment: Theories, tests, and issues, $3^{\text {rd }}$ Edition, Guilford, New York, USA: 99-144.

Shewan CM (1986). The language quotient (LQ): A new measure for the Western Aphasia Battery. Journal of Communication Disorders, 19(6): 427439.

Vygotsky L (1978). Mind in society: The development of higher mental process. Harvard University Press, Cambridge, Massachusetts, USA.

Wechsler D (2014). Wechsler intelligence scale for children. Fifth edition, Pearson, Bloomington, MN. 